\title{
Data access as a means to promote consumer interests and public welfare - An introduction
}

Josef Drexl

\section{A. Introduction}

Digital technologies transform the economy and society. They are the basis of new products and services. Digital technologies are developed by using data, such as for the training of artificial intelligence systems, and their application generates myriads of new data. Making best use of these technologies and the data they generate, in full compliance with the fundamental values of our diverse and democratic society, is key for economic, social and public welfare.

To achieve this goal, policy makers have to identify and develop the appropriate legal framework for the digital economy. There is growing consensus that promoting data access will have to play a central role in this regard. ${ }^{1}$ Yet what the overall legal framework should be and how to implement data access regimes in different fields of the law have so far remained rather unexplored.

The following contributions to this book seek to fill this gap. The book in its entirety aims at clarifying how data access rules can promote consumer interests and public welfare. From the perspective of legal research and policy, this is rather uncharted land. Current law only sporadically provides for data access as a means to regulate private business. This includes the right to portability of personal data as enacted in the General Data Protection Regulation ${ }^{2}$ and data access rights of competitors as part

1 See, in particular, the Communication from the Commission of 19 February 2020 to the European Parliament, the Council, the European Economic and Social Committee and the Committee of the Regions, 'A European strategy for data' $\operatorname{COM}(2020) 66$ final 13, announcing the proposal of a 'Data Act' for 2021 that seeks to promote data sharing and could include, among other things, obligations of private actors to grant access to data.

2 Art. 20 Regulation (EU) 2016/679 of the European Parliament and of the Council of 27 April 2016 on the protection of natural persons with regard to the processing of personal data and on the free movement of such data, and repealing Directive 95/46/EC [2016] OJ L119/1. 
of sector-specific legislation. ${ }^{3}$ The EU has already acquired considerable experience as regards access of private businesses to publicly held data ever since the adoption of the original Public Sector Information (PSI) Directive in $2003 .{ }^{4}$ But, given the fact that today private players are among the most important generators of data, the policy debate now also addresses the question of how diverse public interests can be promoted through access of the state to privately held data. ${ }^{5}$

To introduce the following contributions, this chapter first links consumer interest and public interest grounds, on the one hand, and sketches the general policy considerations that matter for data access regimes, on the other (at B. below). Then, it will specify the legal challenges of using data access regimes for the purpose of promoting consumer interests and public interest grounds (at C. below) and identify overarching questions to which the following contributions seek to provide answers (at D. below). Finally, this chapter sketches the structure of the book (at E. below).

3 See, in particular, the access regime for motor vehicle repair and maintenance information: Arts 6-9 Regulation 715/2007 of 20 June 2007 on type approval of motor vehicles with respect to emissions from light passenger and commercial vehicles (Euro 5 and Euro 6) and on access to vehicle repair and maintenance information [2007] OJ L171/1, as last amended by Regulation (EU) No 459/2012 of 29 May 2012 [2012] OJ L142/16. Equally, European law provides for a right of the providers of digital payment services to seek access to the bank account data of customers: Art. 36 Second Digital Payment Services Directive (PSD2) (EU) 2015/2366 of the European Parliament and of the Council of 25 November 2015 on payment services in the internal market, Directives 2002/65/EC, 2009/110/EC and 2013/36/EU and Regulation (EU) No 1093/2010, and repealing Directive 2007/64/EC [2015] OJ L337/35.

4 Directive 2003/98/EC of the European Parliament and of the Council of 17 November 2003 on the re-use of public sector information [2003] OJ L345/90, which has meanwhile been reformed and replaced by Directive (EU) 2019/1024 of the European Parliament and of the Council of 20 June 2019 on open data and the re-use of public sector information [2019] OJ L172/56.

5 See Communication from the Commission of 25 April 2018 to the European Parliament, the Council, the European Economic and Social Committee and the Committee of the Regions, 'Towards a common European data space' COM(2018) 232 final, 12-14 (on 'business-to-government data sharing'); Commission Staff Working Document of 25 April 2018, 'Guidance on sharing private sector data in the European data economy' SWD(2018) 125 final. 


\section{B. Connecting data access with consumer interests and public welfare}

The legal and economic discourse of the last decades has largely been dominated by the economics-based claim that market regulation should strive to increase economic welfare and efficiency. Safeguarding efficient and competitive markets that also promote innovation (in terms of 'dynamic efficiency') certainly remains a fundamental objective of the future legal framework for the digital economy. However, as regards the digital economy, there are good arguments for extending the spectrum of objectives and including broader public interest goals (see at I. below). The underlying assumption of this book is that data access regimes could promote such goals, while the existing law is not well prepared to provide such access (see at II. below). Therein lies both the challenge for policy makers and the legislature as well as the opportunity for the scholars contributing to this book to reflect about innovative legal solutions.

\section{The impact of the digital economy on consumer interests and public interest grounds}

Digital technologies do not only change how manufacturers produce ('industry $4.0^{\prime}$ ). They also change how we consume, how we communicate and think, and how we make decisions. As consumers, we nowadays have access to many digital services that are offered 'for free'; but we are only able to get access to such services because we are ready to provide personal data. The digital economy also provides us with new possibilities for social exchange, communication and social organisation in groups of 'friends', which has an impact on what we think, what we believe and how we decide as political beings. Big data analysis and artificial intelligence even enables us to delegate our decisions to autonomous agents, whether it is about business or consumer decisions. Hence, the digital economy impacts society - and the life of individuals - in a much broader way with manifold anthropological, ethical and political implications. Far from only challenging modern societies, digital technologies are enormously promising. They even promise to solve most pressing problems of humanity, whether it is about climate change, still untreatable diseases and current and future pandemics, food security and sustainable development of all re- 
gions of the world. ${ }^{6}$ These benefits do not at all argue against economic reasoning as a basis for regulation of the digital economy. Yet they support a more holistic approach that takes the larger spectrum of implications and potential benefits as well as the diverse interests of stakeholders and the public into account.

As regards the group of stakeholders, legislation also has to widen the perspective. Therefore, this book is not exclusively on regulating business. Given the impact on the private life of all of us, consumer interests deserve particular attention. And, finally, the state does not only appear as a regulator, but also as an additional stakeholder with a public interest in access to data.

There is of course the question whether it makes sense to distinguish consumer interests from public interest grounds. Indeed, such distinction hardly makes sense against the backdrop of central laws of economic legislation. In particular, competition law safeguards competitive markets both in the public interest in promoting growth, saving resources and enhancing innovation, and in the collective interest of consumers. This explains why it is commonly argued that competition law aims at promoting 'consumer welfare', which is often understood, especially by neoclassical economics, to indicate 'economic efficiency'. Equally, the unfair trading law of the $\mathrm{EU}$ in $\mathrm{B} 2 \mathrm{C}$ relations protects the 'collective' interests of consumers ${ }^{7}$ and, simultaneously, it constitutes a major part of general market regulation that seeks to enhance transparency and, thereby, contributes to economic welfare in the broader sense. In the context of these laws, characterising collective consumer interests as a particular public interest is also supported by the fact that all citizens are consumers. Even more, other public interest grounds may coincide with particular consumer interests. Guaranteeing the safety of food products and pharmaceuticals is both a collective consumer interest and an aspect of the interest in public health. As regards digital mobility, the goal of guaranteeing safety as regards automated and autonomous driving is both a public interest concern and, as regards the safety of concrete devices, a particular consumer interest.

6 It was the OECD that some years ago highlighted potential benefits of digital innovation in terms of multiple public interest goals from a global perspective. See OECD, 'Data-Driven Innovation: Big Data for Growth and Well-Being' (OECD 2015).

7 Directive 2005/29/EC of the European Parliament and of the Council of 11 May 2005 concerning unfair business-to-consumer commercial practices in the internal market [2005] OJ L149/22. 
Still this equation of consumer interests with a public interest deserves a more nuanced consideration in the context of the digital economy. Traditionally, consumer interests have been understood in terms of economic interests and the interest in protecting the physical integrity and well-being of consumers. In the digital economy, where consumers provide access to their personal data and where access to personal (customer) data drives many digital business models, data protection concerns also have to be integrated in this equation. ${ }^{8}$ In this regard, the role of the fundamental right to data protection and its implementation in the form of the GDPR is rather complex. On the one hand, data protection rules may reduce effective market solutions because they prevent firms of the digital sector from making the best commercial use of personal data. However, data protection also has to be considered a precondition for the development of digital markets and business models to the extent that data protection is needed to build consumer trust in the sense that their privacy interests will be respected especially on the Internet ('trustworthy Internet'). The same applies with regard to anti-discrimination rules. In times of big data analytics and AI-based decision-making, it is important that such automated decisions not be based on biased data and that these decisions not discriminate against certain groups of society ('ethical AI'). In certain instances, data protection interests and the interest in non-discrimination may also collide with the interest of the state in data access. How to balance data protection rules with public interest grounds regarding access to personal data has to be decided through a balancing of the fundamental rights concerned and may lead to very different outcomes for different public interest concerns, such as public health, on the one hand, and preventive crime prevention, on the other hand.

Digitisation influences how consumer interests need to be understood and how they relate to public interests in an even more fundamental manner. Especially the business models of the digital platform economy are designed to collect and generate as much data about the personal preferences of individual customers, and as many customers as possible, to provide them with more targeted offers. Automated AI-based decisions may even replace individual consumer decisions in the consumers' best interest. This may serve individual consumers well, namely, those who appreciate the

8 There is therefore growing literature on the relationship between data protection law and consumer law on the EU level in particular. See, for instance, Natali Helberger, Frederik Zuiderveen Borgesius and Agustin Reyna, 'The perfect match? A closer look at the relationship between EU consumer law and data protection law' (2017) 54 Common Market Law Review 1427. 
convenience and ease these business models provide. However, this challenges modern competition policy, since these consumers are drawn into closed 'digital ecosystems' where consumers increasingly are supplied with diverse goods and services by a single firm without feeling the need to shop elsewhere. ${ }^{9}$ This may lead to a digital economy where the market structure tends to foreclose market access to newcomers, which may be highly innovative but lack sufficient knowledge about customer preferences as a precondition for market success. This shows that individual consumer interests tend to get disconnected from the public interest in an open, procompetitive and innovative digital economy.

Beyond these more economics-based considerations, digitisation also affects the political process and the functioning of democracy. Foremost, this is so because digital business models are based on data as carriers of information and thereby have the potential of fundamentally transforming the markets for ideas. When justifying and exploring the need for regulation of social platforms, which are today among the major providers of political information and ideas, we can of course rely on known economics-based theories. We can argue that those platforms are characterised by a market failure of adverse selection since exclusively business-driven, unregulated social platforms will not guarantee the quality (especially the 'truthfulness') of news. To reject the argument that in digital echo-chambers consumers receive exactly the kind of information and opinions they prefer, we find support in behavioural economics, informing us that users of social media are affected by a confirmation bias when they choose their preferred source of information. Yet all of these economics arguments also express a paternalistic attitude vis-à-vis the individual consumer. Although these arguments may provide rational explanations for the problem, they do not give an answer to the question on how paternalistic regulation can get with a view to guaranteeing the functioning of the democratic process and against the backdrop of the fundamental rights of these consumers to freedom of expression and information. This shows that the digital economy raises fundamental constitutional questions and the need to make decisions on the fundamental rules of both commercial and political interactions of modern society.

9 On competition among digital ecosystems, see, among others, the report of the Special Advisors to the EU Commissioner for Competition: Jacques Crémer, YvesAlexandre de Montjoye and Heike Schweitzer, 'Competition policy for the digital era - Final report (2019) 3-4, 11, 13-14, 30-38<https://ec.europa.eu/competition/p ublications/reports/kd0419345enn.pdf> accessed 31 August 2020. 
The advent of 'digital consumption' marks another feature of the digital economy that displays a truly anthropological dimension. As 'digital consumers' we receive preselected and more targeted offers based on our past personal decisions as well as empirically inferred preferences based on the consumption habits of 'people like us'. Building on such 'past and inferred' preferences, AI-based automated decision making can replace real consumer decisions. Of course, everybody has a choice whether and to what extent one wants to become such a 'digital consumer'. However, it is another question what 'digital consumerism' does to a democratic society where a constantly increasing number of people delegate daily decisions to anonymous digital agents. This raises the anthropological question of whether and how the delegation of daily economic decisions and the assessment of the pros and cons of such decisions will affect the ability of citizens to take into account the negative consequences of their political decisions.

Indeed, a democratic society has to build on free and responsible citizens. Where, as a consequence of digital business models, consumers lose their data autonomy and sovereignty, they risk losing their ability to act as free citizens when they make political decisions. Therefore, data protection in the digital economy should also be considered a public interest concern.

In sum, this shows that the legislature is confronted with a most complex field of economic regulation with very diverse concerns that often have both a private and a public interest dimension. Data access rights will typically address particular market failures in economic terms or serve a particular individual or public interest. But because of the broader political and societal implications, data access regimes also need to respect the fundamental values and rights of the democratic society and should be based on, or allow for, appropriate balancing with conflicting, potentially very diverse interests.

\section{Data as the object of access rights}

Legal rules on the data economy have to take into account that data are economic assets with very peculiar features. Indeed, they are often of enormous competitive and monetary value. However, this does not justify metaphors such as the 'oil of the twenty-first century'. In contrast to exhaustible natural resources, data as informational goods are non-rival in nature. Hence, economic welfare will typically increase by data sharing. This is what drives the conviction that society will in principle benefit from the free flow of data, even more where access to data can help address 
fundamental public interest concerns and modern challenges for humanity, such as public health and pandemics, environmental protection and climate change, food security and poverty.

Yet data access may also come with a price. Investment in data collection and generation as well as control over data are major drivers of competition. Therefore, from an economic perspective, data access should in principle only be ordered where such access addresses a specific market failure, serves to solve a problem of competition, such as market foreclosure, or enables innovation of the data access claimant. Conversely, the legislature should refrain from adopting data access regimes that allow for free-riding on the investment of competitors and reduce incentives for innovation.

Moreover, the existence of sensitive data - personal data and trade secrets - needs to be taken into account. These data deserve special protection against dissemination. Yet the sensitivity of data does not need to exclude data access as such. Anonymisation and confidentiality obligations as part of the terms and conditions of access can often enable sufficient access while respecting the legitimate interest in keeping the information secret.

\section{Data access and the law}

In the current situation, the law does not seem well prepared for enhancing data access. Competition law as the fundamental law of the free market economy that applies across sectors of the economy could in principle work as a basis for a duty to grant access to data. This is possible in the framework of the prohibition of abuse of market dominance, where a refusal to grant data access appears as a sub-category of general refusals to deal. ${ }^{10}$ Yet, even if dominance can be shown, enforcers may be rather reluctant to argue a duty to deal, since such duty conflicts with freedom of contract as a paramount principle of the free market economy. In addition, competition law cannot serve as a basis for rules on access of the state to

10 EU competition law has some, albeit limited, experience in this regard. See, in particular, Joined Cases C-241/91 and C-242/91 RTE and ITP v. Commission ('Magill') [1995] ECR I-743 = ECLI:EU:C:1995:98 (on the duty of TV broadcasters to license the copyright protecting the programming information to independent TV guide publishers); Case T-201/04 Microsoft v. Commission [2007] ECR II-3601 = ECLI:EU:T:2007:367 (on the duty of Microsoft to grant access to interoperability information to allow competitors to program competing work-group server operating systems that are compatible with Windows). 
privately held data, even less where access would promote other public interest concerns than safeguarding competition.

Of course, data access could also be promoted by general private law. However, the very idea of data access seems opposed to the fundamental exclusivity paradigm of property law regarding physical assets. There is a real danger that the identification of data as an economic asset and as a tradable good will tempt policy makers and scholars alike to rely on ownership concepts when framing the private law of data. The need to protect the integrity of data through general tort law may equally support the view that the exclusivity (property) paradigm should also be applied to data, especially in jurisdictions such as the German one where tort law in principle requires an infringement of absolute rights. Yet these attempts would fundamentally ignore the very nature of data as non-rival informational assets. In sum, this may support protection of the integrity of data in favour of the data holder under tort law, but still argue against the recognition of an exclusive right with erga omnes effects to use data in follow-on markets.

In addition, there is a need to develop contract law for the digital economy. In B2B relations in the digital economy data have already become an object of transactions. Since the digital economy often builds on cooperation between firms, and firms frequently generate data within networks (so-called 'co-generated data'), there is of course a need for the interested parties to be able to decide on the rules that are supposed to govern the generation of data as well as access to and use of data. De facto data holding and the possibility to protect against access through technical protection measures already seem to provide enough factual exclusivity to enable transactions on data access and sharing, without additional legislation being needed. Still, recognition of data access rights remains an absolute innovation within the realm of statutory contract law. ${ }^{11}$

Moreover, the question of how to design the legal framework for the digital economy currently challenges all jurisdictions. Given the very different constitutional background and, even more, different attitudes of jurisdictions regarding the right to data protection, it is clear that the answers will differ. Yet the challenges extend beyond borders. Many digital business models, especially those of the Internet platform economy, are designed for global markets. Connected devices are sold in international mar-

11 See, however, the new data access right of consumers under Art. 16(4) Directive (EU) 2019/770 of the European Parliament and of the Council of 20 May 2019 on certain aspects concerning contracts for the supply of digital content and digital services [2019] OJ L136/1. 
kets. Therefore, this book discusses the future legal framework for access rights primarily for legislation on the level of the EU as a Union of shared values and with the establishment of an internal market as the centrepiece of its economic objectives.

From a perspective of research, the topic of this book provides significant scope for legal innovation. Data access is an issue that regards multiple fields of the law, including in particular contract law, competition law, intellectual property and data protection law. Similarly, given the constitutional implications and the data protection dimension, as well as the involvement of the state as both a big data holder and a stakeholder that increasingly seeks data access, research on future access rights has to overcome the traditional separation of private law and public law. Furthermore, the future legal framework requires a balancing of most diverse individual and public interests in different parts of the law. The different fields of the law all have their own traditions, and all were framed in the era of the analogue economy. This means that all fields of the law also individually have to adapt to the digital economy. Yet the traditional objectives of the different fields of the law will remain relevant and set limitations to their potential of enhancing data access. This may result in the need of parallel and partially overlapping access regimes of different laws to reach optimal results. In sum, research on the future legal framework of the 'network' economy is best advised to take a holistic 'network' approach that simultaneously looks at different fields of the law and the interactions between them.

Of course, legal research also has to take account of extralegal disciplines to get a proper understanding of the factual issues and context. Even more, to enhance data access, it is not sufficient to concentrate on legislative measures regarding the legal relationship between the different players of the data economy. Data access also depends on the availability of multiple technologies and institutional arrangements, such as standard-setting bodies and procedures, platforms for data sharing and data trustees, which again may be in need of regulation. Of course, legal research on market regulation has to rely on economic insights to identify market failures that data access rights are supposed to address and to predict the effects of regulatory measures. Since consumers play a major role, insights from other social sciences and psychology may also advance better legislation. In sum, this shows that the appropriate policy approach to promote the data economy has to be based on insights from different research disciplines, and the necessary legal measures should be embedded in a broader 'data governance approach' that also promotes the necessary technologies and institutional arrangements. 


\section{Towards the future of data access rights}

This book is about the need for future rules on data access. Advocating new rules to regulate the economy always requires caution. Rules are not needed where the market provides appropriate solutions. Based on this, key questions arise that will in principle be relevant for all contributions in this book.

The very first question regards the default rule. Should this rule be 'access by default' or 'exclusivity by default'? At this stage of development, the rule tends towards the latter. Firms are allowed to control 'their' data. Even where they cannot rely on intellectual property rights to control access to data, they can use technical protection measures to exclude others. Legal recognition of de facto data exclusivity is far from economically unsound, since such exclusivity will often be a prerequisite for data transactions based on contract law that ultimately leads to data access and data sharing. Therefore, unrestricted data access should not be the rule since optimal access and optimal use is not without costs. Data access frequently requires investment in data quality and technical arrangements to enable access. Therefore, de facto data holders should in principle be allowed to deny access with the objective of securing remuneration for providing access. In a market economy, contract law and the principle of freedom of contract is in principle the most efficient means to allocate costs among different parties.

As regards data access regimes, the question will therefore be what market failures and what interests will justify a deviation from exclusivity. This question will answer the question where and to what extent 'exclusivity by default' should shift to 'access by default'. It is here that especially consumer interests, data protection interests and public interest grounds will need to be balanced to define the scope and design of data access regimes.

Many follow-on questions will relate to the design of access regimes: What are the data that should be covered? Only personal data or also nonpersonal data? What about 'derived' data, such as anonymised aggregated data, or 'inferred' data, meaning data generated through empirical assessment of correlations between pre-existing data? Who should be vested with access rights, competitors, consumers or the state? What does a duty to grant access actually mean, only an obligation to provide access to the informational content, transfer of digitally encoded data at a given time or permanent sharing of data, including real-time data?

Granting access rights raises follow-on questions regarding the terms and conditions of access. A duty to grant access to data can be seen as a kind of compulsory licensing system under which a data holder is required 
to enter into an agreement that allows the other party to use the data at certain terms. Follow-on questions especially regard whether the data holder should be allowed to charge a price or at least claim compensation for the costs of providing data access. What should be the principles for calculating such remuneration or compensation? Another question regards liability of the data holder for the quality of the data. Additional institutional arrangements may be needed to enhance voluntary contracting against the backdrop of legal access regimes, such as collective agreements of business entities, standardisation of data formats and application programming interfaces (APIs), data trustees and institutions for mediation and arbitration.

In the EU context, another question will be to what extent solutions should be transferred to the European level and how much flexibility Member States should be granted to follow national approaches.

\section{E. Structure of the book}

The first group of contributions seeks to answer the question whether there is a need for additional access regimes or what justifies new data access rules. The first two contributions do so in the light of general public policy arguments and economics. A contribution on competition law as a basis for data access, and its need for reform in this regard, will prepare the transition to the following contributions.

Then, as part of the second group, several contributions concentrate on the larger legal framework for data access. This includes the constitutional framework and the data protection rules of the General Data Protection Regulation (GDPR). Another contribution analyses the impact of exclusive intellectual property rights as well as trade secrets protection on data access and seeks to accommodate both interests in protection and access in identifying future building blocks for the regulation of the data economy.

The third group of contributions takes stock of existing data protection regimes and their future potentials for the regulation of data access. Two contributions look at the contract law system, one focussing on the fairness control of contract terms, the other one on existing and future data access rights as part of statutory contract law. Within the EU, the most prominent and discussed data access right is the right to portability of personal data under Article 20 GDPR, which another contribution analyses as a potential blueprint for additional data access regimes. Yet another contribution takes a look at data access rights of competitors as part of European sector-specific regulation and its implications for innovation. Finally, against the backdrop of a taxonomy of access rights and based on a com- 
parative approach, the last chapter of this group seeks to investigate what lessons can be learned from data access regimes adopted in various other jurisdictions around the globe.

The final group of contributions looks at new approaches to legislation on data access regimes. This is introduced by a contribution that highlights the need for embedding data access regimes in larger sets of measures as part of more comprehensive data governance regimes. The two remaining contributions focus on more specific new access regimes, namely, regarding data access rights of the users of connected devices for which an unfair competition law approach is discussed, on the one hand, and government access to privately held data ('B2G data sharing') in the public interest, on the other hand. 
